\title{
Laboratory Test Reason Not Done
}

National Cancer Institute

\section{Source}

National Cancer Institute. Laboratory Test Reason Not Done. NCI Thesaurus. Code C83313.

The rationale why a laboratory test was not performed. 